\title{
SISTEMAS TUTORES INTELIGENTES COMO RECURSO DIDÁTICO NO ENSINO DA MATEMÁTICA
}

\author{
R.L. CARVALHO ${ }^{1}$, R.G. CABRAL ${ }^{2}$, Y.R. FERRER ${ }^{3}$ \\ Universidade do Estado do Amazonas ${ }^{1,2}$ \\ Universidade de la Habana ${ }^{3}$ \\ jessiehero@yahoo.com ${ }^{3}$
}

Artigo submetido em 28/02/2018 e aceito em 11/12/2019

DOI: $10.15628 /$ holos.2019.7028

\section{RESUMO}

As tecnologias de informação e comunicação oferecem recursos de apoio ao processo educacional. O presente trabalho tem como objetivo potencializar a elaboração e uso de novas ferramentas tecnológicas que venham a contribuir como recurso didático no processo ensinoaprendizagem. Nesta perspectiva, com a ideia de utilizar o computador como uma ferramenta no auxilio didático, apresenta-se um protótipo, desenvolvido atendendo aos requisitos de fundamentos de Sistemas Tutores Inteligentes (STI). Neste caminho, foi implementado o software educacional, sob STI, para solucionar ou minimizar problemas de assimilação de conteúdos matemáticos, no qual os alunos sejam capazes de registrar informações relevantes, fazer exercícios e provas, gerenciar consultas e retornos de atividades, emitir relatórios, visualizar notas e rendimento. Para avaliar a usabilidade do protótipo foi aplicado um questionário aos professores da disciplina, concluindo-se a relevância do sistema desenvolvido para proporcionar um ambiente de aprendizagem adaptado as necessidades do aluno.

PALAVRAS-CHAVE: Softwares educacionais, Sistemas tutores inteligentes, Ferramenta pedagógica, Ensino da matemática.

\section{INTELLIGENT TUTORING SYSTEM AS A DIDACTICAL RESOURCE FOR MATHEMATICS TEACHING}

\begin{abstract}
Information and communication technologies provide resources to support the educational process. The present work aims to potentiate the elaboration and use of new technological tools that contribute as didactic resource in the teaching-learning process. In this perspective, with the idea of using the computer as a teaching aid tool, it is presented a prototype developed following the foundations of Intelligent Tutoring Systems (ITS). In that idea, an educational software was implemented to solve or to minimize assimilation
\end{abstract}

problems of mathematical contents; wherein the students are capable to register relevant information, to do exercises and exams, to manage hints and feedback of activities, to emit reports and to visualize notes and progress. To evaluate the usability of the prototype, a questionnaire was applied to mathematics teachers, concluding the relevance of the system developed to provide a learning environment adapted to the student's needs.

KEYWORDS: Educational software, Intelligent tutoring systems, Pedagogical tool, Mathematics teaching 


\section{INTRODUÇÃO}

A aplicação de recursos tecnológicos oriundos das pesquisas envolvendo as Tecnologias da Informação e Comunicação (TIC) não é nova no contexto educacional. É cada vez mais comum o apoio ao processo de ensino-aprendizagem proporcionado pelos recursos tecnológicos. E devemos pôr a tecnologia a serviço do processo educacional, ampliando possibilidades e proporcionando alternativas para que o aluno construa e produza seu próprio conhecimento.

De acordo com Viccari (1996, p.10), as TIC têm se tornado objeto de maior investigação por parte dos pesquisadores da área de Informática aplicada à Educação, considerando a fluente utilização de técnicas de Inteligência Artificial (IA) em projetos de desenvolvimento de ambientes de ensino-aprendizagem computadorizados. Isto, devido às suas potencialidades, para, a partir deste processo, propor intervenções no ensino convencional, ressaltando a autoaprendizagem auxiliada pelos recursos computacionais.

Nesta perspectiva, este projeto tem a ideia de utilizar o computador como ferramenta de auxilio didático a partir do trabalho com o mesmo, buscando automatizar processos de ensino e acompanhamento, como um dos sistemas de atividades instrucionais. Será trabalhado com base em fundamentos de Sistemas Tutores Inteligentes. Este software tem como principal objetivo realizar a tarefa de ensino de um dado conteúdo (domínio), na forma mais adaptada ou que se aproxime às necessidades do aluno.

Em síntese, serão utilizadas técnicas de inteligência artificial e teorias pedagógicas para conduzir o estudante, proporcionando um ótimo ambiente de aprendizagem. Enfim, o projeto tem a finalidade de criar um software educacional que possibilite ao aluno um ambiente de aprendizagem, com seus modos de entendimento, buscando provocar interação com o sistema.

\section{REVISÃO BIBLIOGRÁFICA}

Esta pesquisa tem como finalidade tornar possível um modelo de aprendizagem que se aproxime das características dos processos mentais do estudante ao longo da aprendizagem. Alguns teóricos, como Carbonell (1970), Giraffa (1999) e Goulart (2001), afirmam que: "agentes inteligentes no projeto de STI permitem uma melhor interação entre tutor e aluno, possibilitando a investigação de processos mentais a nível mais estratificado" (Viccari, 1996, p.12). Contudo, começaremos pela estrutura clássica dos Sistemas Tutores Inteligentes para se buscar o sistema pretendido pelos autores citados.

Assim, pretende-se a promoção de novas ferramentas para a educação, baseada na tecnologia de STI's, que tenha as funções de tutorar o aprendizado nas dificuldades encontradas pelos alunos da Escola Municipal Maria Nira Guimarães - que é a lógica matemática, e que o STI tenha a capacidade de instruir e contribuir com o aprendiz na disciplina de matemática com exercícios referentes ao 5 ㅇ ano do Ensino Fundamental. 
2.1 Sistemas inteligentes na contribuição disciplinar e didática do processo ensinoaprendizagem

Atualmente, encontram-se disponíveis vários tipos de software educacional como também muitas pesquisas sobre o tema - as novas tecnologias na educação. Para contribuir com meio didático e como ferramenta de ensino, contribuindo expressivamente para práticas escolares, se destaca hoje a inserção de um software que trabalha a aprendizagem computadorizada com a modelagem de Sistema tutor Inteligente (STI) que promove a interação entre o aluno (usuário) e o sistema.

Os sistemas tutores inteligentes são uma classe de sistemas de inteligência artificial que atuam como auxiliares no processo de ensino-aprendizagem de alunos. São sistemas inteligentes, aplicados à educação, que permitem a criação de um ambiente cooperativo entre aluno, sistema e professor. (Dahmer, 1999).

O uso de software tem acarretado melhoras quanto à qualidade pedagógica ou quanto à relação ensino-aprendizagem. Sendo que o software educacional oferece um ótimo recurso como ambiente de aprendizagem. Em destaque, estão os SistemasTutores Inteligentes para auxiliar a aprendizagem e abordar um software capaz de tutorar uma pessoa em um determinado conteúdo, em que o STI "sabe o que ensinar", o "como ensinar", e aprende informações relevantes sobre o aluno que está sendo tutorado.

Segundo Chaves (como citado em Dahmer 1999), esta abordagem incentiva à troca de paradigma do modelo de ensino tradicional, centrado no professor, para um novo, centrado no aluno e baseado no "aprender a aprender".

$\mathrm{Na}$ observação dos processos de aprendizagens na escola, notaram-se vários problemas com relação a alguns conteúdos, como a leitura e as operações matemáticas. É sabido que esta é uma realidade do ensino escolar, principalmente em instituições públicas. Isso ocorre porque os professores também têm na sua forma de trabalho dificuldades em sala de aula, por constantemente estarem ocupados com várias atribuições do universo acadêmico, por enfrentarem estruturas precárias trabalhistas, bem como por terem suas salas de aula superlotadas, além do pouco reconhecimento que se faz do papel deste profissional.

\subsection{A Matemática no STI}

A ideia de se trabalhar com STI como recurso didático no ensino da matemática, vem ser ainda uma maior dificuldade nas escolas. Atualmente, o principal desafio para os pais e professores é estimular o gosto e a prática da aprendizagem. Muitas vezes, tanto em casa quanto na escola, faltam iniciativas que favoreçam a aprendizagem, não somente o simples ato de transmitir seus conteúdos, mais pelo fato de ser estimulada a criatividade, curiosidade e desenvoltura.

Analisando a realidade, observamos que o ensino da matemática é questionado pelos alunos, por ser vista como uma disciplina de difícil compreensão, que desmotiva e muitas vezes sua aplicação não tem relevância com o cotidiano. 
O problema não está só na aprendizagem, mas na forma como a matemática é ensinada. Todavia, a consequência ocorre com os elevados índices de reprovação e evasão, já que os alunos não conseguem ver como válida sua aprendizagem.

Por isso é necessário elaborar projetos e metodologias que despertem nos alunos interesse, que os estimule e desenvolvam habilidades de pensamento. Primeiro tornando a matemática mais perto do cotidiano do aluno, deixando-a mais interessante aos olhos dos alunos, dessa forma perceberão que os conhecimentos aprendidos em sala de aula, poderão ser utilizados fora do ambiente escolar, pois como afirma D'Ambrósio (1996, p.98): "tudo que se nota na realidade dá oportunidade de ser tratado criticamente com um instrumental matemático", em que o mesmo dá exemplo dos jornais, que todos os dias trazem muitos assuntos que podem ser explorados matematicamente".

Para se alcançar os objetivos esperados para o ensino-aprendizagem da Matemática, devese levar em conta também o conhecimento prévio do aluno, para desejarmos uma aprendizagem significativa. Aprendizagem significativa segundo Moreira et. al (1997, p.1):

É o processo através do qual uma nova informação (um novo conhecimento) se relaciona de maneira não arbitrária e substantiva (não-literal) à estrutura cognitiva do aprendiz. Uma relação não arbitraria e substantiva significa que as ideias são relacionadas a algum aspecto relevante existente na estrutura cognitiva do aluno.

Nesta perspectiva ausebeliana, o conhecimento prévio (a estrutura cognitiva do aprendiz) é a variável mais importante, e quando ele estabelece significado destes com os novos conhecimentos a aprendizagem significativa acontece.

O que se busca com o sistema tutor é a valorização do conhecimento prévio do aluno e a aprendizagem significativa, e ele vêm como um material potencialmente significativo. Viana (2011, p.19) explica que um material significativo é um material que possui significado lógico ou potencial, e os seus elementos estão organizados em uma estrutura e não apenas sobreposto de forma arbitrária.

Neste contexto, a elaboração de material didático sendo apoiado computacionalmente, atuando no campo da tecnologia com sistemas de assessoramento para o ensino-aprendizagem da disciplina, os objetivos matemáticos podem ser explorados com a utilização de jogos e desafios, pois estes favorecem o desenvolvimento moral, social e emocional da criança. Eles "apresentam situações-problemas, onde as crianças são desafiadas a utilizar seus esquemas mentais na construção da resolução" Fonseca (1997, p.59) como citado em Silva (2013, p.6). Com a criação de um software educacional, sob STI, tem-se a possibilidade de deixar as aulas mais motivadoras e significativas.

Contudo pensando nas maiores dificuldades dos alunos, a elaboração deste projeto visa colaborar com os professores em suas práticas metodológicas, como recurso didático junto aos alunos. 


\section{O PROJETO DE SOFTWARE}

A ideia do sistema originou-se dos modelos de software que chegassem mais próximo possível ao nível de conhecimento do aluno, a criação de um protótipo embasado nas ideias dos seguintes autores: Carbonell (1970), Giraffa (1999) e Goulart (2001). O Protótipo desenvolvido tem como objetivo trabalhar assuntos de matemática do 5o ano do Ensino Fundamental em atividades de: Aritmética Básica, Medidas de peso, Medidas de Tempo, Medidas de Comprimento, Jogos de Operações e a Lógica, para desenvolver uma aprendizagem significativa no aluno, em que o software dê uma automação ao usuário em relação sua aprendizagem.

A questão mais complexa encontrada, quanto a contribuição na criação de um software, que faça uma abordagem individual e que exerça de um modo entendido o que o usuário consegue passar de resultados ao sistema, em que o mesmo possa analisar as informações e passar o retorno do que ele aprendeu. A maioria dos softwares encontrados não possibilita a avaliação sequencial, como fator finalizador da interação com a máquina, se houve e até que ponto houve aprendizagem e estímulo. Em geral, fica apenas no "jogar por jogar".

Com base nas colocações acima, a questão centrada fica em vir a analisar essas informações, e mostrar ao usuário o que ele está aprendendo e como está indo seu desenvolvimento, ou seja o objetivo foi desenvolver um tutoramento que ajude o aluno a tomar decisões e que venham a suprir um não-entendimento.

\subsection{Arquitetura Proposta}

A arquitetura descrita é baseada nos primeiros STI's, como o sistema SCHOLAR e outros trabalhos como o WHY e SOPHIE, que são descritos no trabalho de Wenger citado em Goulart (2001, p. 5.). Estes tutores são os primeiros Sistemas Tutores Inteligentes baseados na estrutura clássica. A Figura 1 abaixo representa a arquitetura clássica ampliada por Self, em que a mesma é melhor esplanada no trabalho de Goulart (2001).

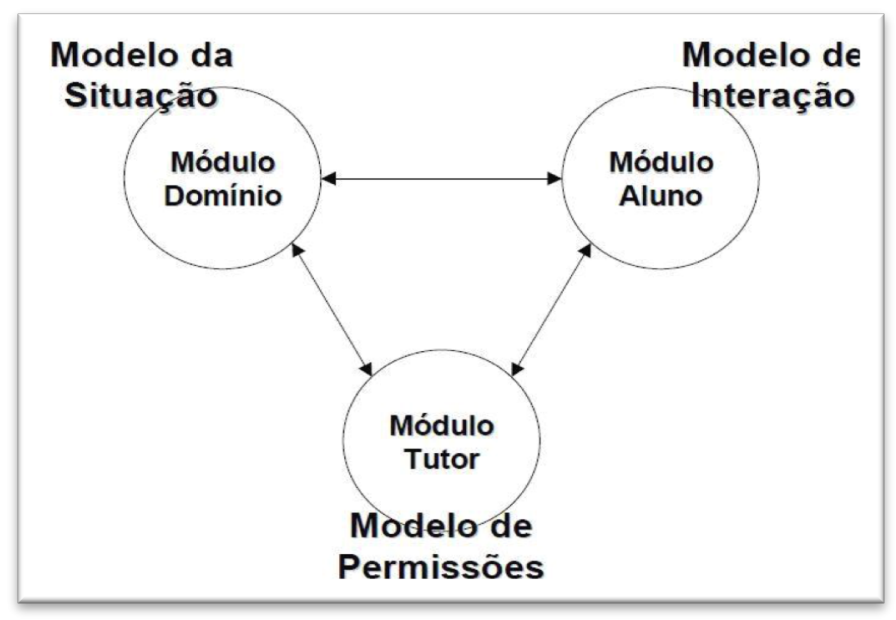

Figura 1: Arquitetura clássica de um STI ampliado por Self (FONTE, Goulart e Giraffa, 2001) 


\subsubsection{O Tutor}

A estrutura básica de um STI é composta por quatro modelos: Interface, Domínio, Aluno e Tutor. Com a interação desses modelos, o STI é capaz de julgar os conhecimentos do aprendiz e seu desenvolvimento.

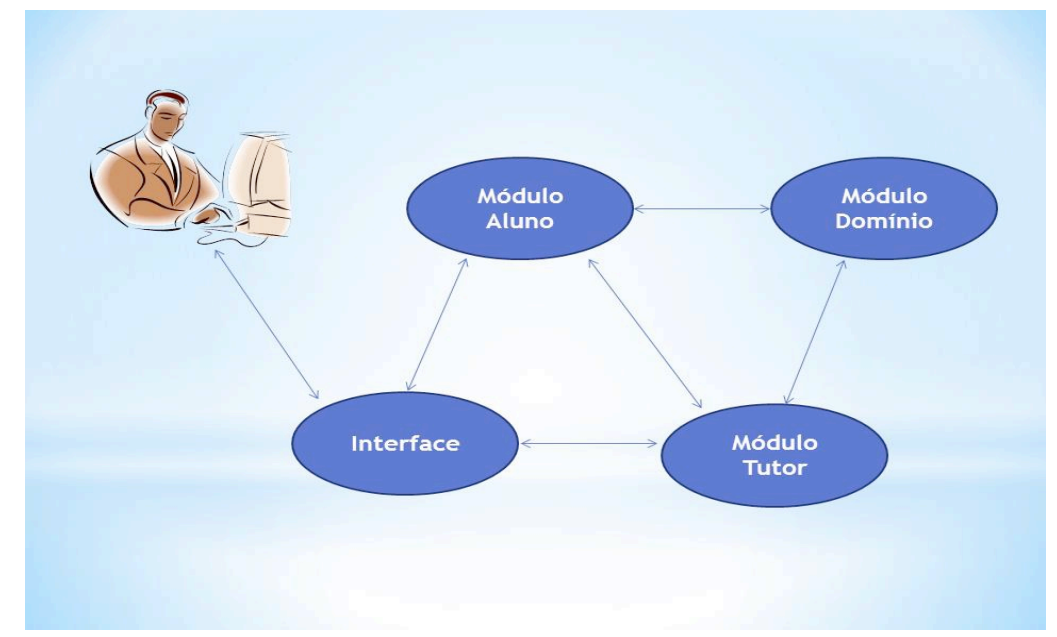

Figura 2: Arquitetura clássica de um STI (FONTE, Goulart e Giraffa, 2001)

- O modelo da Interface refere-se à interface utilizada pelo STI para efetuar a comunicação com o aprendiz.

- O modelo do Domínio representa o conhecimento que o STI possui sobre o assunto que ele está tutorando.

- O modelo do Aluno identifica as concepções e o desempenho do aluno.

- O modelo do Tutor exerce o controle sobre a seleção e a sequência de informação que é passada ao aprendiz, e determina quando o aprendiz precisa de ajuda e que tipo de ajuda é necessário.

Goulart (2001, p.6) comenta que

esta arquitetura é denominada de clássica e também conhecida como funcional tripartida ou tradicional de STI. O termo tripartida se refere às funções associadas aos módulos tutor, do aluno e domínio. Esta proposta trouxe grandes avanços à modelagem de ambientes educacionais, pois separou o domínio da sua forma de manipulação (no sentido de utilização). Permitindo, assim, que estratégias de ensino fossem associadas em função das informações oriundas da modelagem do aluno.

Logo a baixo imagens dos modelos representados pelo protótipo de software educacional baseado em STI.

\subsection{Desenvolvimento do Protótipo do Sistema Tutor Inteligente}

Nesta etapa, serão descritas as características do protótipo do Sistema Tutor Inteligente desenvolvido, em representação, apenas o diagrama de atividades. 


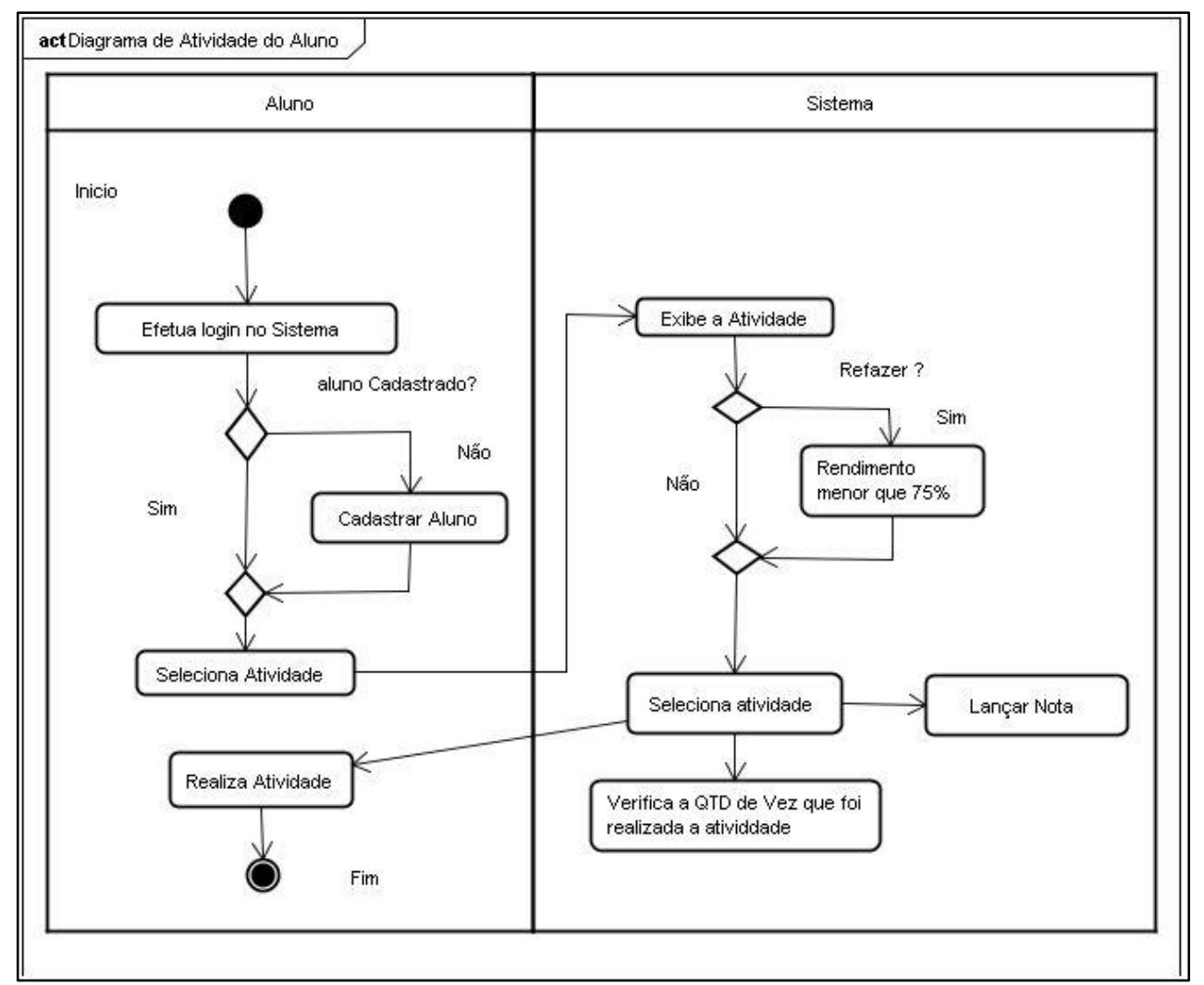

Figura 3: Diagrama de atividades de interação do Aluno. Fonte: Renato Lopes.

O diagrama de atividades representa o processo de Atividade do aluno com interação no sistema, apresentado na Figura 3. O processo inicia com a efetuação de Login e logo verifica-se se o aluno possui cadastro. Após a entrada no sistema o aluno escolhe determinado conteúdo de atividade para praticar. Caso o aluno seja um usuário frequente, de certas atividades, o sistema antes de exibir a atividade comunica ao aluno que o mesmo possui exercícios com o rendimento menor que $75 \%$. O aluno então, tem a opção de escolher se deseja refazer dada atividade com a respectiva "nota baixa" para melhorá-la ou se deseja continuar de onde o mesmo parou. Feitos esses passos, o aluno continua sua interação com o sistema, podendo escolher outras atividades.

\subsubsection{Representações do Modulo Tutor}

Nessa arquitetura o modelo Tutor trabalha junto ao modelo do aluno e domínio, ditando os procedimentos a serem tomados em determinadas interações com o aluno (usuário). Como esta modelagem possui características de sistema clássico, Goulart e Giraffa $(2001$, p.6) conceituam o modelo tutor como aquele que: "possui o conhecimento sobre as estratégias e táticas para selecioná-las em função das características do aluno (representadas no módulo aluno)".

Pelo conhecimento do módulo do aluno e do módulo do domínio, o tutor saberá tomar as decisões concomitantes a ele, a tomada de decisões pedagógicas em função da interação com o aluno, como afirma Goulart (2001) "o tutor utiliza o modelo do aluno e do modelo de domínio para tomada das decisões didáticas e pedagógicas". Ele acrescenta que as decisões afetam a sequência de representação do conteúdo, desta forma com assuntos relacionados, é realizada uma 
adaptação a representação dos tópicos as necessidades do aluno. A Figura 4 indica o exemplo de atuação do Tutor na tomada de decisões.

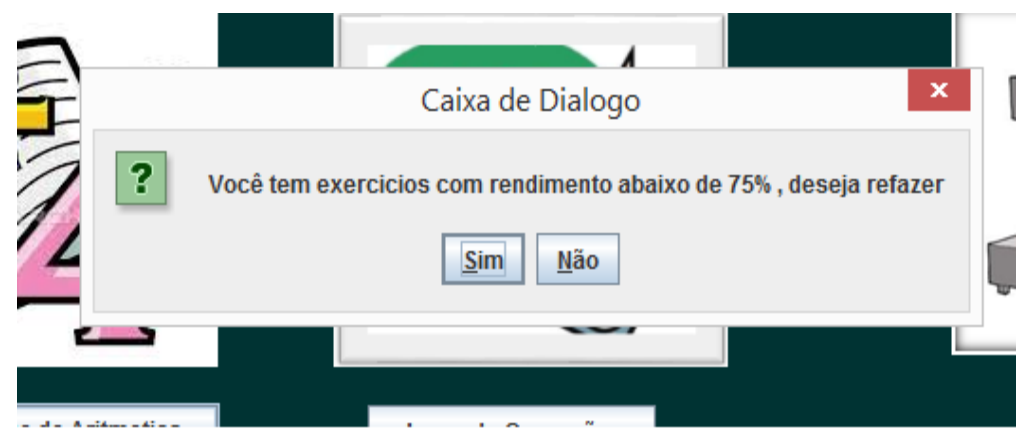

Figura 4: Modelo de tomada de decisões pedagógicas. Fonte: Renato Lopes

Por essa modelagem e implementação de estratégia e tática de ensino é que ele promove a participação do aluno. Este deixou de ser só o responsável pela seleção do conteúdo e estratégias de ensino, vincula-se a se tornar, de uma forma mais ampla, a conduzir o aluno de acordo com objetivos e desafios educacionais que o ambiente proporciona.

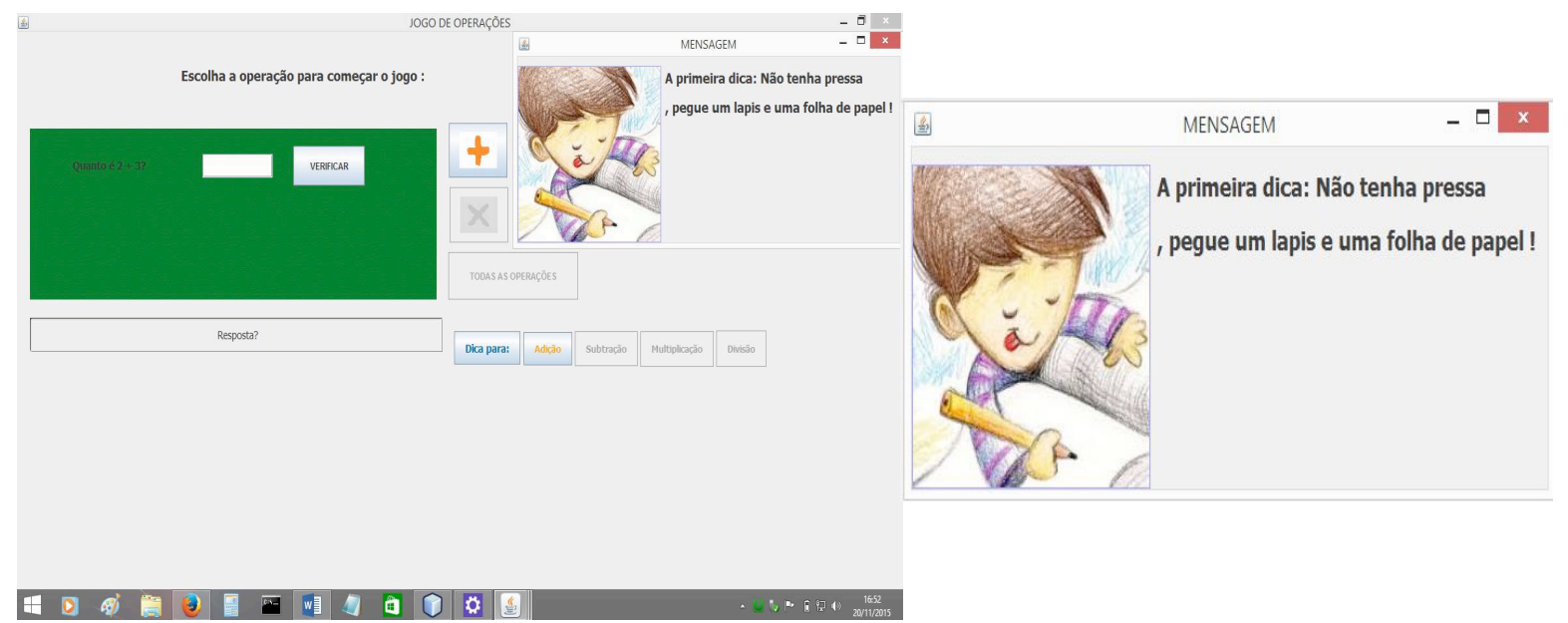

Figura 5: Modelo de Facilitador. Fonte: Renato Lopes.

O protótipo também veio para complementar o ensino na sala de aula, atuando como um facilitador, como mostrado na Figura 5, seu objetivo pode ser descrito em função do seu "comportamento". Para Giraffa apud Goulart $(2001$, p.13) "facilitador é: o agente que monitora o aluno todo o tempo, porém não é diretivo, ele apenas dá dicas sobre a resolução do problema e só intervém quando solicitado".

\section{RESULTADOS DO PROTÓTIPO}

A composição do resultado se constituiu em aplicar um questionário para captar as análises de usabilidade do protótipo desenvolvido. Com um questionário específico ao professor, cujo o mesmo é composto por perguntas relacionadas ao Protótipo do Sistema Tutor Inteligente, se o mesmo atende aos requisitos de adequação ao nível de conhecimento respectivo do 50 ano do Ensino Fundamental, se virá a contribuir ao raciocínio lógico do aluno, teve a exposição do protótipo aos professores para uma análise antes de responder as questões, assim contribuíram 
para justificar os requisitos de usabilidade até aos que estimulam a interatividade. Logo a baixo alguns gráficos referentes ao questionário aplicado.

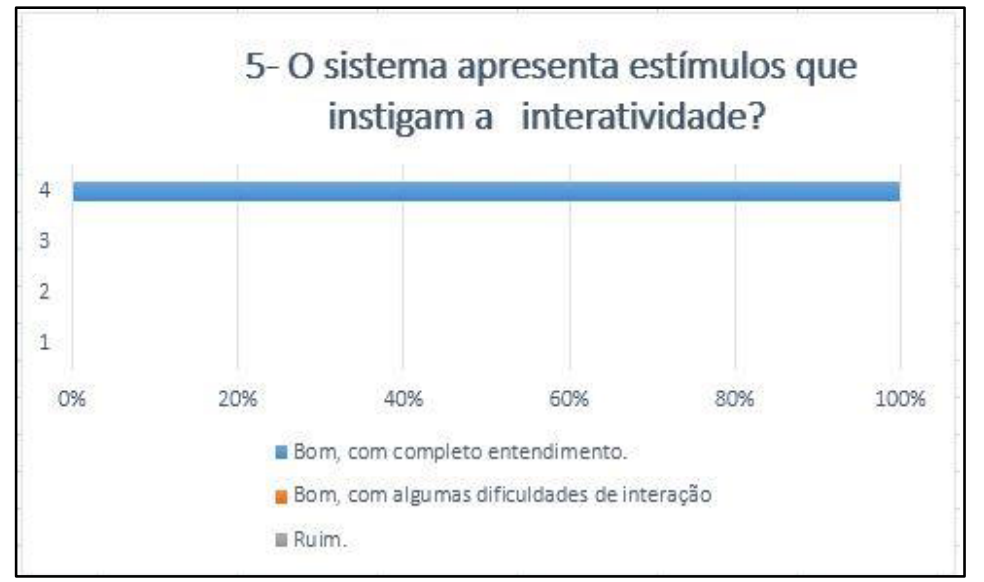

Figura 6: Gráfico - O Sistema Estímulos que instigam a interatividade. Fonte: Renato Lopes.

A análise corresponde tanto aos processos de mensagens, quanto aos processos de abordagens didáticas. Sobre isto se pode lembrar que, na atualidade, constantemente, professores optam por utilizar softwares educativos nas aulas de Informática, possibilitando aos alunos a interatividade com os jogos, permitindo aprimorar seus conhecimentos adquiridos através de teorias na sala de aula. A ação da interatividade por Piaget citado em Morais (2013, p.15) na descrição de sua teoria: "O conhecimento é construído interativamente entre o sujeito e o objeto".

Na medida em que o sujeito age e sofre a ação do objeto, sua capacidade de conhecer se desenvolve, enquanto produz o próprio conhecimento. Assim, a proposta de Piaget é reconhecida como construtivista interacionista.

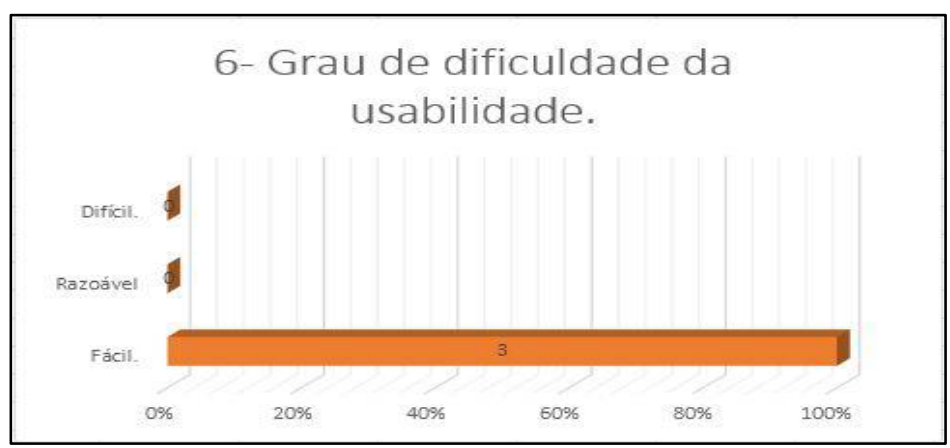

Figura 7: Gráfico - Grau de dificuldade de Usabilidade. Fonte: Renato Lopes.

Na Figura 7 mostra-se a usabilidade nas interfaces está baseada em princípios heurísticos, para totais compreensões dos usuários. Alves (2012) comenta as principais vantagens do estudo da usabilidade de um produto de software são as seguintes:

- Aumentar a produtividade dos utilizadores

- Aumentar os níveis de utilização do produto

- Reduzir a necessidade de formação e de custos de produção de documentação.

- Reduzir os custos de suporte técnico 
- Reduzir custos e tempo de desenvolvimento

- Minimizar o re-desenvolvimento e as alterações após a finalização

Quanto a este critério avaliativo, o grau de usabilidade foi relativamente fácil e bem compreendido pelo uso-teste dos professores participantes, fator que ajuda na questão de implementação, pois serão então apenas melhor adaptadas as interações e níveis de complexidade.

\section{CONCLUSÃO}

Concluindo os estudos que foram feitos, para ver a real problemática, e prover medidas através da Informática na Educação. Pela pesquisa, foi adquirida informação que os programas utilizados em processos administrativos escolares ou em contextos pedagógicos são considerados softwares educacionais, que estes promovem desenvolvimento no cognitivo do aluno.

Foi possível elaborar um STI, com a ideia do uso de softwares que potencializem e deem um espaço diferenciado e que promovam de forma aberta e descontraída o aprendizado. 0 mesmo tem característica em auxilio na aprendizagem baseado no tutoramento, sendo tarefa diferencial do STI, em que ele sabe o que ensina, como ensina, isso possível pelo modo de aprender informações relevantes do usuário.

Contudo o desenvolvimento do trabalho se constituiu em apresentar um protótipo com fundamentos em STI, visando colaborar com os professores em suas práticas metodológicas, e avaliar sua usabilidade junto aos professores, para que seu objetivo principal de implementação seja alcançado. Igualmente, comprovou-se que depois da inserção das TIC nas escolas os professores também resolveram produzir metodologias de inserção das tecnologias, tornando suas aulas plugadas no processo de informatização.

\section{REFERÊNCIAS}

Alves, R., de Mattos, D., Martins, C., dos Santos, L.H. (2012). A utilização das TIC no ensino das escolas públicas: refletindo sobre fatores que influenciam seu uso. ticEDUCA2012 II Congresso Internacional TIC e Educação, Lisboa, Portugal. Recuperado de http://ticeduca.ie.ul.pt/atas/pdf/283.pdf.

Carbonell, J. R. (1970). Al in CAl: An Artificial-Intelligence Approach to Computer-Assisted Instruction. IEEE Transactions on Man-Machine Systems, 11(4), 190-202. https://doi.org/10.1109/TMMS.1970.299942.

D’Ambrosio, U. (1996). Educação Matemática: Da teoria à Prática. Campinas, SP: Papirus.

Dahmer, A., Gaspary, L.P., Frozza, R., dos Santos, C.T., Sperb, J.K, Pereira, T.C. (1999). Ambiente Integrado de Apoio ao Ensino a Distância: Gerenciamento de Aulas, Tutores Inteligentes e Avaliação Remota. Memorias del Taller Internacional de Software Educativo TISE’99, Santiago 
de Chile, Chile. Recuperado de

http://www.c5.cl/ieinvestiga/actas/tise99/html/papers/ambiente/.

Giraffa, L., \& Viccari, R. (1999). Estratégias de Ensino em Sistemas Tutores Inteligentes Modelados através da Tecnologia de Agentes. Revista Brasileira de Informática na Educação, 5(1), 9-18. doi:http://dx.doi.org/10.5753/rbie.1999.5.1.9-18.

Goulart, R.R., \& Giraffa, L.M. (2001). Arquiteturas de sistemas tutores inteligentes. Relatório Técnico 011, Faculdade de Informática, PUCRS, Brasil. Recuperado de http://www3.pucrs.br/pucrs/files/uni/poa/facin/pos/relatoriostec/tr011.pdf.

Goulart, R.R. \& Giraffa, L.M. (2001). Utilizando a Tecnologia de Agentes na Construção de Sistemas Tutores Inteligentes em Ambiente Interativo. Simpósio Brasileiro de Informática na Educação (SBIE), Porto Alegre, Brasil. Recuperado de http://www.brie.org/pub/index.php/sbie/article/view/154.

Morais, R. (2003). Software educacional: a importância de sua avaliação e do seu uso nas salas de aula (Trabalho de conclusão de curso). Faculdade Lourenço Filho, Fortaleza, Brasil. Recuperado de $\quad$ www.pucrs.br/ciencias/viali/tic literatura/monografias/monografia-rommelxenofonte.pdf.

Moreira, M.A., Caballero, M.C. E Rodríguez, M.L (orgs). (1997). Aprendizagem significativa: um conceito subjacente. Actas del Encuentro Internacional sobre el Aprendizaje Significativo. Burgos, España. pp. 19-44. Recuperado de http://www.if.ufrgs.br/ moreira/apsigsubport.pdf.

Silva, M.F., Cortez, R.C.C., Oliveira, V. (2013). Software Educativo como auxilio na aprendizagem da matemática: uma experiência utilizando as quatro operações com alunos do 4o ano do Ensino Fundamental. Revista Educação, Cultura e Comunicação, 4(7).

Viana, O. (2011). Conhecimentos prévios e organização de material potencialmente significativo para a aprendizagem da geometria espacial. Ciências \& Cognição, 16(3). Recuperado de http://www.cienciasecognicao.org/revista/index.php/cec/article/view/698.

Viccari, R.M. (1996). Sistemas tutores inteligentes: abordagem tradicional x abordagem de agentes. XIII Simpósio Brasileiro de Inteligência Artificial, Tutorial - T6, Curitiba, Brasil. Recuperado de http://www.trabalhosfeitos.com/ensaios/Sistema-TutoresInteligentes/937945.html. 